\title{
ASPECTOS SOCIOCULTURAIS DO TRANSTORNO DE DÉFICIT DE ATENÇÃO E HIPERATIVIDADE NA INFÂNCIA
}

\author{
Marcos Venicio Esper ${ }^{1}$ \\ EERP/USP \\ Naiara Barros Polita ${ }^{2}$ \\ EERP/USP \\ Jeferson Santos Araújo 3 \\ Universidade Federal da Fronteira Sul - UFFS \\ Lucila Castanheira Nascimento 4 \\ EERP/USP
}

\section{RESUMO}

Por meio de um ensaio de caráter teórico-reflexivo, procurou-se identificar os aspectos socioculturais do Transtorno de Déficit de Atenção e Hiperatividade. Com a finalidade de explorar as distintas concepções do transtorno de déficit de atenção e hiperatividade e discutir elementos capazes de favorecer sua compreensão, na expectativa de contribuir para melhor desempenho dos profissionais da educação e da saúde no manejo das questões sociais e culturais. Desde o conceito de instabilidade mental ao campo moderno da genética e as diferentes culturas, a criança que apresenta comportamento hiperativo e perturbador é, geralmente, conduta considerada inaceitável pelos adultos e profissionais da saúde e educação, o que pode comprometer o diagnóstico e o tratamento. À luz dessas considerações, evidencia-se a relevância de sempre analisar e refletir o lado adulto impondo regras e limites, e o lado da criança vivendo sua essência infante.

Palavras-chave: Infância; Criança; TDA/H; Cultura.

\footnotetext{
${ }^{1}$ Mestre em Ciências da Saúde - UNIFESP; Doutorando em Ciências - Programa Interunidades - USP.

${ }^{2}$ Universidade Estadual do Norte do Paraná (UENP). Centro de Ciências Biológicas - Setor Enfermagem.

${ }^{3}$ Curso de Graduação em Enfermagem; Universidade Federal da Fronteira Sul, Campus Chapecó; Rodovia SC 484 Km 02, Fronteira Sul, Bloco dos Professores.

${ }^{4}$ Departamento de Enfermagem Materno-Infantil e Saúde Pública; Escola de Enfermagem de Ribeirão Preto, Universidade de São Paulo. Centro Colaborador da OPAS/OMS para o Desenvolvimento da Pesquisa em Enfermagem.
} 


\title{
SOCIOCULTURAL ASPECTS OF ATTENTION DEFICIT HYPERACTIVITY DISORDER IN CHILDHOOD
}

\begin{abstract}
Through a theoretical-reflective essay, we sought to identify the sociocultural aspects of ADHD (Attention Deficit Disorder with or without Hyperactivity). In order to explore the different concepts of ADHD and discuss elements capable of favoring their understanding, in the expectation of contributing to better performance of education and health professionals in the management of social and cultural issues. From the concept of mental instability to the modern field of genetics and different cultures, the child who exhibits hyperactive and disturbing behavior is generally a conduct considered unacceptable by adults and health and education professionals, which can compromise diagnosis and treatment. In the light of these considerations, the relevance of always analyzing and reflecting the adult side by imposing rules and limits, and the side of the child experiencing its infant essence is evident.
\end{abstract}

Keywords: Childhood; Child; ADHD; Culture.

\section{Introdução}

O Transtorno de Déficit de Atenção e Hiperatividade (TDA/H) consiste em uma desordem do neurodesenvolvimento cuja prevalência mundial varia de $5.3 \%$ a $7.1 \%$ em crianças e adolescentes (ADHD INSTITUTE, 2018). Os sintomas do TDA/H, impulsividade, desatenção e hiperatividade, podem causar problemas comportamentais, sociais e baixo desempenho escolar (MULHOLLAND, CUMMING, JUNG, 2015).

Comumente, os professores são os primeiros a identificar e fornecer informações para o diagnóstico do TDA/H, além de serem fundamentais para o desenvolvimento das habilidades sociais e aprendizado dessas crianças (NOGUEIRA, 2015; MULHOLLAND, CUMMING, JUNG, 2015). Entretanto, estudos sobre as experiências e perspectivas de professores demonstram que eles encontram desafios diários para o manejo em sala de aula da desatenção e dos problemas de comportamento decorrentes do TDA/H (LAWRENCE, ESTRADA, MCCORMICK, 2017; NOGUEIRA, 2015). Os educadores preocupam-se com o futuro das crianças, julgam-se responsáveis por seu aprendizado e sentem-se culpados pelas dificuldades de interação com os alunos que possuem este transtorno (LAWRENCE, ESTRADA, MCCORMICK, 2017). Além disso, referem conhecimento insuficiente para lidar com essas situações e demonstram o desejo de aprender mais sobre o TDA/H e receber maior suporte institucional (NOGUEIRA, 2015; MULHOLLAND, CUMMING, JUNG, 2015; LAWRENCE, ESTRADA, MCCORMICK, 2017).

Na psiquiatria infantil, o TDA/H é, provavelmente, o tema mais estudado na atualidade. Os pedopsiquiatras franceses defendem concepções diferenciadas do transtorno, que consideram também fatores ambientais e socioculturais (WELNIZARZ, 2011).

Ainda há discussões na literatura sobre o TDA/H ser mais bem conceituado como uma desordem biológica ou construção cultural. Para Rohde (2005) e Nakamura (2007), não há dúvidas da existência de diferenças significativas nas demandas que surgem no contexto do ambiente (familiar, escolar, entre outros) de acordo com os aspectos culturais. Além disso, a expectativa e 
a tolerância para certos comportamentos variam em diferentes grupos culturais, de modo que os padrões para comportamentos normais e desviantes são socialmente determinados. Dessa maneira, as atitudes e ações da família e dos profissionais da educação são igualmente influenciadas pela cultura.

Segundo Duarte (2013), o TDA/H instituiu-se, fortemente, nos Estados Unidos e foi quase completamente desconsiderado com relação a crianças na França. A autora traz uma reflexão profunda: TDA/H é um transtorno biológico ou neurológico? Surpreendentemente, a resposta a esta pergunta depende se a criança vive na França ou nos Estados Unidos, responde a autora. No Brasil, as estimativas de prevalência de TDA/H em crianças e adolescentes também variam amplamente, com valores entre $0,9 \%$ e $26,8 \%$ (ANVISA, 2014).

Nos Estados Unidos, os psiquiatras pediátricos consideram o TDA/H como um distúrbio biológico, com causas biológicas. $O$ tratamento de escolha também é biológico -medicamentos estimulantes psíquicos, tais como Ritalina e Adderall (DUARTE, 2013).

Já os psiquiatras infantis franceses, por outro lado, veem o TDA/H como uma condição médica que tem causas psicossociais e situacionais. Em vez de tratar os problemas de concentração e de comportamento com drogas, os médicos franceses preferem avaliar o problema subjacente que está causando o sofrimento da criança; não o cérebro da criança, mas o contexto social da criança. Eles, então, optam por tratar o problema do contexto social subjacente com psicoterapia ou aconselhamento familiar. Esta é uma maneira diferente de ver a questão, comparada à tendência americana de atribuir todos os sintomas de uma disfunção biológica a um desequilíbrio químico no cérebro da criança (DUARTE, 2013).

Em Portugal, a sigla utilizada para o TDA/H é PHDA (Perturbação de Hiperactividade e Défice de Atenção). O PHDA é uma perturbação do neurodesenvolvimento (Fonseca, 2017) com elevada prevalência em crianças, o que provoca desafios às escolas e às famílias devido às suas características conhecidas como a desatenção, agitação motora e impulsividade. A autora sublinha que as crianças e jovens com PHDA representam um constante desafio para as suas famílias, porque, devido às suas características têm, por vezes, comportamentos disruptivos e desafiantes que, seja em ambientes públicos, escolares ou no contexto familiar, causam embaraço à família, mal-estar e desconforto aos presentes que, frequentemente, fazem juízos de valor sobre a educação e regras dadas às crianças (DE OLIVEIRA, 2020).

Aqui está a validação de que a doença é socialmente construída, ou seja, para se estar doente depende de qual cultura o sujeito está inserido. A saúde mental é o resultado do equilíbrio dinâmico entre a criança e seu meio ambiente, nossos corpos e mentes são profundamente afetados por nossas experiências sociais, pois há uma concatenação entre a vida social, a mente e o corpo.

Diante do exposto, este artigo caracteriza-se como um ensaio reflexivo. Buscou-se, a partir da antropologia da saúde pensar e explorar distintas concepções do TDA/H, discutir elementos capazes de favorecer sua compreensão, na expectativa de contribuir para melhor desempenho dos profissionais da educação e da saúde no manejo das questões sociais e no bem-estar dessas crianças. Utilizou-se como referência fontes de investigações científicas, articulando-as com diferentes noções e contextos sobre a temática. $O$ artigo é dividido em (3) três seções: Evolução histórica do TDA/H; Midiatização e medicalização do TDA/H; Cuidar e educar a criança com TDA/H.

A noção de saúde e doença deve privilegiar as causas, bem como identificar e combater em diferentes ângulos, de acordo com Gonçalves, 2004: 
[...] pela antropologia médica (também designada por antropologia da saúde), surgindo no campo da psiquiatria e da antropologia social trabalhos de autores como (Devereux, 1981; Laplantine, 1991; Kleinman, 1988, 1992; Good, 1986, 1994; Helman, 1994; Eisenberg, 1988; Quartilho, 1995, 2001). Estes autores ao estudarem a forma como os aspectos socio-culturais influenciam a saúde, a doença e os processos de cura, ressaltam que, em todas as sociedades humanas, as crenças, atitudes e práticas relacionadas com problemas de saúde são características fundamentais de uma cultura, do complexo cultural dos indivíduos e das populações (p. 161).

Salienta-se que a definição ocidental de uma visão contemporânea de saúde, a definição declarada pela Organização Mundial da Saúde (OMS) expressa uma leitura positiva baseada no bem-estar físico, mental e social. No entanto, esse bem-estar é difícil de definir fisicamente, sobretudo em questões relacionadas à saúde mental. Se o modelo médico era uma fonte primária de inspiração, sua aplicação no campo dos transtornos mentais mostra uma série de inadequações. Portanto, o TDA/H convoca elementos socioculturais e subjetivos.

\section{Evolução histórica do TDA/H}

O conceito de instabilidade mental, desenvolvido por médicos franceses entre 1887 e 1910, raramente é mencionado e muitas vezes ignorado e estudos desse período mostram que a instabilidade mental corresponde ao conceito atual de TDA/H, introduzido em 1887 por Bourneville, um neurologista francês, no Hospital Bicêtre, em Paris. Para chegar a essa concepção, ele observou crianças e adolescentes descritos como "anormais" e mantidos em instituições médicas e educacionais (BADER, 2015).

Data de 1919 a primeira classificação, feita por Paul Bancour (apud PETITOT, 2007), de crianças consideradas contrárias à integração escolar, às quais foi atribuído o termo "indisciplinado". Nessa classificação, distinguiam-se os indisciplinados pervertidos, os indisciplinados instáveis sem perversão e os indisciplinados instáveis e pervertidos.

Havia também um debate se a questão da indisciplina era de ordem natural orgânica ou psicoafetiva, mas os psicanalistas sustentaram a origem psicoafetiva dessas dificuldades, por eles atribuída a uma dificuldade de organização psíquica de uma criança ligada, essencialmente, a determinado contexto de desenvolvimento. Essa concepção perdurou até os anos 80 , quando foi elaborado o DSM (Manual Diagnóstico e Estatístico Mental), que adotou a seguinte classificação: "reação hipercinética da infância". Esse diagnóstico, entretanto, não poderia ser usado se o transtorno fosse consequência de uma lesão cerebral, pois precisaria ser avaliado como uma reação secundária relacionada a diversas dificuldades encontradas no entorno familiar e/ou social (PETITOT, 2007).

A instabilidade da criança, com suas diversas denominações - transtorno de déficit de atenção com ou sem hipercinésia, agitados, desatentos, impulsivos, etc. - é plural em nível etiológico, diagnóstico e terapêutico. Em muitos indivíduos, apresenta-se de maneira diferente, a depender do funcionamento intrapsíquico e intersubjetivo (JOLY, 2003).

Nesse sentido, Fourneret (2003) e Günter (2015) apresentam diversos fatores, tanto endógenos (os avatares do desenvolvimento da personalidade da infância) quanto exógenos (a problemática parental muito recorrente nas relações com a infância), o que suscita uma discussão de ordem psicodinâmica. Quando se define a hiperatividade na infância como uma patologia de ação, alimenta-se a esperança de, eventualmente, superar a polêmica, sempre presente na prática clínica. Todavia, torna-se um argumento cientificamente obsoleto entre os defensores do tudo psicodinâmico e os do tudo orgânico e restaura na área da psicopatologia a possibilidade de 
um debate entre disciplinas associadas, cujo objetivo comum sempre foi compreender a natureza do ato e dos estados mentais (FOURNERET, 2003).

É possível perceber também no olhar dos defensores da psicopatologia, uma dualidade: de um lado desejam compreender as manifestações de hiperatividade no contexto psicológico e relacional, mas, de outro, defendem uma abordagem médica rigorosa para caracterizá-la como uma desordem neurológica, o que justificaria o uso de tratamento medicamentoso e terapia cognitivo-comportamental (CHAGNON, 2005).

Uma sociedade cada vez mais movida pelo "agir", que mantém a ilusão de ser possível se redimir de qualquer ato mediante tratamento puramente comportamental, parece, é verdade, algo mais tentador e menos oneroso do que o esforço necessário, e às vezes doloroso, para o desenvolvimento psíquico de condutas. De fato e provavelmente, mais que qualquer outra patologia da infância, a hiperatividade tornou-se a figura emblemática de uma oposição ideológica entre duas visões causais dos fenômenos psicocomportamentais: a primeira, em referência ao modelo psicanalítico freudiano, atribui a inquietação a uma intencionalidade oculta em resposta emocional, essencialmente, intersubjetiva e inconsciente; a segunda, ao contrário, sem motivação evidente, manifesta para algumas crianças a expressão de um déficit do controle e/ou de planejamento de conduta, cuja origem deve ser investigada na esfera neurobiológica e pode, por conseguinte, justificar a oportunidade de tratamento de correção ou regulação (CHAGNON, 2005).

Desde o início do século XXI tem-se visto uma veloz expansão de pesquisas no campo da neuropsicologia infantil que trazem uma constante questão de fundo: a hiperatividade patológica da criança, como uma entidade clínica, realmente existe? Ou é, como muitos profissionais da saúde e da educação ainda querem, um mito (Fourneret, 2003) para legitimar a prescrição de anfetaminas para crianças, cujo comportamento disruptivo incomoda o adulto? Percebe-se que o modelo biomédico, que orienta a assistência à saúde, em especial aqui representado por psiquiatras e pediatras, não considera essas questões. Até mesmo diante de uma manifestação sintomática, em que faria sentido somente observar a compreensão da organização psíquica do sujeito e a evolução de suas modalidades relacionais, medicamentos milagrosos são prescritos (FOURNERET, 2003).

A hiperatividade infantil divide as opiniões entre os especialistas da psiquiatria infantil, pois não envolve apenas questões teórico-clínicas e terapêuticas, mas também culturais, sociais e políticas. Sabe-se que esses fatores, na comunidade "psi", normalmente são compartilhados e propagados rapidamente (CHAGNON, 2005).

Chagnon (2005) considera a hiperatividade dita essencial ou pura como manifestação sintomática de processos psicopatológicos, de modo que a particularidade não reside somente em ser negligenciada por alguns pediatras ou psiquiatras, que refutam o princípio psicodinâmico capaz de detectar o processo patológico, essencialmente silencioso com baixas manifestações sintomáticas mentais. Tal processo pode ser denominado de psicopatologia branca, assintomático, convocando a clínica do negativo e se manifestando por uma hiperexpressividade temperamental, comportamental. Nos últimos anos na área da psiquiatria infantil, observa-se o retorno de modelos médicos "duros", cujos objetivos se apoiam parcialmente na classificação americana (DSM) e, em parte, na prática profissional. Nota-se também que a psicologia cognitiva e a neuropsicologia, modelos que visam explicitamente erradicar o pensamento psicopatológico, têm privilegiado a etiologia e o orgânico de alguns transtornos ainda vistos isoladamente do resto do funcionamento mental, em uma postura de desconsiderar não só a história do indivíduo, mas também o contexto ambiental, relacional e social em que se passa para atribuir-Ihes um significado. 
A maioria dos grandes estudos sobre dimensões culturais dos diagnósticos psiquiátricos infantis no DSM concentrou-se em uma comparação das taxas de prevalência de diagnósticos entre grupos étnicos ou nações. Eles enfatizam a confiabilidade, embora geralmente dedicasse pouca atenção à validade e ao significado dos padrões de sintomas em um determinado sistema social (KLEINMAN, 1988). As poucas pesquisas na América do Norte que usaram os critérios do DSM-IV em uma amostra da comunidade para comparar grupos étnicos em termos de risco para transtornos psiquiátricos infantis destacam as semelhanças nas taxas de prevalência diagnósticas entre crianças indianas, mexicanas, europeias, africanas, porto-riquenhas e americanas (Angold, 2002 Costello, 1996; Canino et al., 2004 apud Rousseau, 2008). Uma grande pesquisa ( $n=4.175)$, com base em uma amostra de jovens entre 11 e 17 anos, fornece dados abrangentes sobre perfis de diagnóstico DSM para jovens europeus, africanos e mexicanos americanos nos EUA. Os resultados mostram que os jovens afro-americanos tiveram taxas de prevalência mais baixas desordem em comparação com outros grupos pesquisados, apesar do status de minoria em desvantagem. Contudo, verificou-se que essas diferenças étnicas desaparecem amplamente ao se ajustar ao comprometimento e às covariáveis (Roberts et al., 2006a; Roberts et al., 2006b). A constatação de que o status social desfavorecido não parece, por si só, aumentar o risco de desordem entre os jovens minoritários, é consistente com os resultados de estudos canadenses comparando dificuldades emocionais e comportamentais entre Khmer e adolescentes refugiados da América Central, bem como entre adolescentes imigrantes caribenhos e filipinos e seus pares nascidos no Canadá (ROUSSEAU et al 2008). Paralelamente a esse quadro global, estudos que examinam entidades diagnósticas discretas tendem a fornecer descobertas complexas sobre o papel da cultura nos transtornos psiquiátricos infantis.

Segundo Zayats (2019), o TDA/H é um distúrbio clinicamente definido, e a desatenção e hiperatividade / impulsividade são seus principais domínios dos sintomas. A apresentação, continuação ao longo da vida e resposta ao tratamento dos sintomas do TDA/H, no entanto, é altamente heterogênea. Os ramos da genética, recentemente em evolução, podem elucidar a farmacologia do TDA/H (farmacogenética) e os efeitos ambientais críticos para os aspectos clínicos do TDA/H: efeitos econômico-genéticos, geno-epidemiológicos, epigenéticos e pais de origem (ZAYATS, 2019).

Desde o conceito de instabilidade mental, apresentado no início desse tópico, ao campo moderno da genética, destaca-se a ideia de Gingerich (1998), por relatar que em muitas culturas, as crianças que apresentam comportamento hiperativo e perturbador é, geralmente, conduta considerada inaceitável pelos adultos. A extensão em que um comportamento se apresenta é intolerável e, de alguma maneira, influencia e rotula os critérios de diagnóstico, tratamentos ou ações adotadas.

\section{Midiatização e medicalização do TDA/H}

Esses modelos supracitados são largamente midiatizados e participam da narcisação de uma sociedade cada vez mais intolerante com os conflitos internos e externos, que espera por soluções mágicas, sobretudo se capazes de favorecer poderosos interesses financeiros e políticos (CHAGNON, 2005), ainda que isso ocorra à custa do desenvolvimento mental, certamente mais incerto, mais angustiante e menos imediato.

Nesse aspecto, Golse (2003) assume que o título de seu artigo é um tanto quanto provocador: "A Hiperatividade da criança: uma escolha da sociedade" justificando que quanto mais agitada está uma sociedade, menos ela tolera a hiperatividade de suas crianças. 
As mudanças socioculturais contemporâneas interferem fortemente nas características do funcionamento mental, no sentido de acentuar a recusa do desenvolvimento psíquico de conflitos: o grau de repressão comportamental de excitação para permanecer civilizado abre potencialidades de somatização. A atmosfera repressiva que se levantou nos últimos anos não tem qualquer utilidade se não vier acompanhada de uma reflexão sobre os paradoxos verticalmente impostos às crianças, fundamentados na violência e nos modelos projetados para o futuro. As tendências na defesa e nos investimentos motores e fálicos, acompanhadas de uma diminuição na eficiência, culpa, tolerância à frustração e do aumento da dependência do ambiente e da busca por estímulos prazerosos, incidem mais facilmente em meninos, enquanto as meninas utilizam, mais frequente e precocemente, suas capacidades de sedução em busca de um espelho para se valorizarem e projetarem positivamente seu exterior. Assim, em um mundo moderno, onde se intensifica cada vez mais o bombardeio de excitações, e tentar dominá-las é uma influência em detrimento da satisfação, é mesmo de se admirar, sem subestimar o peso de eventuais vulnerabilidades somáticas, que nossas crianças sejam agitadas e não possam se agitar diante de alguns? (CHAGNON, 2005).

A questão da hiperatividade infantil, de sua identificação e seus contornos clínicos é uma questão difícil tanto pela especificidade clínica deste transtorno quanto pela dimensão sociológica, e até mesmo política, que envolve a escolha das melhores estratégias de cuidados para intervir sobre essa patologia - ou ao menos designá-la. Isso explica o fato da hiperatividade infantil estar no primeiro plano de questões contemporâneas na psicopatologia infantil (ROMAN, 2003; CALIXTO, 2021).

No entanto, o que é patológico em determinada época, pode ser normal em outra. Em termos de hiperatividade da criança, alguns elementos precisam ser relativizados. Para Golse (2003), não somente porque G. Canguilhem nos ensinou que a normalidade não é mais que estatística, mas, fundamentalmente, por causa da tolerância de uma sociedade no que diz respeito à agitação de suas crianças bem como se baseia também em critérios educativos e uma representação da infância, eminentemente, variáveis.

Atualmente, fala-se cada vez menos do sujeito e do sofrimento, mas teoriza-se mais a respeito de sintomas. Nesse sentido, os projetores midiáticos iluminam, por exemplo, a violência de crianças e adolescentes, o mau trato sexual, os transtornos obsessivo-compulsivos (TOC), etc. A tentação é grande, então, de pesquisar e buscar respostas medicamentosas para rapidamente suprimir o sintoma, sem, contudo, fazer uma análise psicopatológica completa da situação, geralmente lenta e plurifatorial (DE SOUSA, 2021; PRADO-MARTIN, 2015; GOLSE, 2003).

Ao escutar os participantes de sua pesquisa-ação, Beltrame (2015) afirma que crianças não têm suas opiniões escutadas, sequer validadas pelos familiares ou profissionais que as diagnosticam, bem como estudo de Brostolim (2021) ao destacar sobre as crianças enquanto sujeitos de direitos, produtores de culturas e de saberes, que precisam ser escutadas e respeitadas.

Segundo Golse (2003), a hiperatividade gradativamente adquire um status clínico particular, e desenvolvem-se, como uma mania no público em geral e nos meios de comunicação, tratamentos do tipo anfetamínico. Na França, no entanto, ela não se tornou uma situação caricatural, tal como observado em outros países europeus e anglo-saxões. É este, portanto, de um lado o fundo cultural da midiatização da hiperatividade de crianças e, de outro, uma tentativa insistente de conceitualizar e categorizar fenômenos com base em modelos preestabelecidos. Nossos modelos (implícitos ou explícitos) comandam as práticas (GOLSE, 2003).

Em consonância com essas ideias, Golse (2003) afirma que as práticas terapêuticas dependem dos conceitos e modelos teóricos. Trata-se, portanto, de uma guerra ideológica, uma discussão 
de fundo que se faz pertinente em termos de escolhas teórico-clínicas, visto que impactam diretamente nas opções das práticas terapêuticas.

Embora algumas crianças apresentem incontestável melhora após prescrição de um tratamento medicamentoso, questiona-se o motivo deste tratamento sintomático dispensar uma reflexão com a criança e seus pais quanto ao significado de suas dificuldades na trajetória de sua existência.

Para Rosa (2011), os problemas psicomotores de atenção dificultam a aprendizagem da criança. Entretanto, quando relacionados ao suposto TDA/H - dificuldades de atenção e características como impulsividade e hiperatividade - não têm origem orgânica. Pelo contrário, primeiramente advêm das relações interpessoais para depois serem internalizados e processados de maneira subjetiva e singular por cada criança. Consequentemente, entende-se que uma intervenção adequada deva ter como foco não somente a criança em si - o indivíduo - mas também as relações psicossociais por ela estabecidas, suas atividades, os processos de escolarização e o meio social e cultural no qual está inserida.

Conhecer novas propostas terapêuticas, e refletir sobre como utilizá-las, pressupõe, irredutivelmente, referenciar um modelo polifatorial que considera a existência de fatores endógenos e exógenos de extrema importância (GOLSE, 2003).

Como exemplo, Gilloots (2002), apresenta um projeto terapêutico: o Centro de Acolhimento Terapêutico em Tempo Parcial (Centre d'accueil thérapeutique à temps partiel - CATTP), que propõe às crianças uma experiência terapêutica grupal, quinzenalmente. Os encaminhamentos a esse grupo ocorrem por várias razões: desarmonia evolutiva ou psicótica, patologia narcísica, característica ou sintomatologia aparentemente isolada, hiperatividade infantil ou inibição. A proposta reside em oferecer cuidado intensivo a crianças com algum problema escolar, comportamentos perturbadores ou dificuldade de aprendizagem e a ajudar aquelas cujas famílias têm dificuldades de assumir este cuidado e assegurar a regularidade escolar. Já em 2014, a mesma autora ressalta que o grupo, como o jogo, tem a ambição de vincular pensamento de ação e ação de pensamento. O conteúdo peculiar da estrutura do cuidado possibilita considerar a atitude da criança não como uma passagem ao ato, transgressiva, mas como uma "passagem pelo ato" que pode ser, em uma estrutura terapêutica, elaborativa. O grupo terapêutico é um transformador, pois ao coletivizá-lo, ele fornece novas formas que o vinculam a representações. O semblante, a constância e o trabalho associativo dos adultos apóiam o grupo que é uma experiência de estímulo para a criança hiperativa de sua capacidade de brincar e agir (GILLOOTS, 2013).

\section{Cuidar e educar a criança com TDA/H}

O limite - linha que delimita territórios próximos - está ligado diretamente ao espaço intersubjetivo, à construção da subjetividade na relação com o outro. Falhas nesta esfera irão se manifestar no comportamento da criança quando ela não estiver adaptada ao seu ambiente e diante de algum perturbador do espaço social.

Quais são as particularidades da falha de limites na hiperatividade? Gilloots (2013) responde a essa questão destacando quatro pontos:

1. O corpo da criança - A questão é, primeiramente, focada no corpo da criança, no seu movimento e nas suas transformações. A agilidade é uma espécie de desafio às leis da gravidade, da negação do perigo, de modo que a criança sobe, rasteja, salta de um ponto 
para outro, em uma postura de explorar todas as possibilidades. No caso de uma criança hiperativa, a dificuldade para integrar as limitações ou manter atenção em determinada atividade é clássica, o que a faz ser descrita como impaciente e impulsiva; é incapaz de sustentar esforço de atenção e, frequentemente, se esquece de suas atividades. A dificuldade que essas crianças apresentam de simbolizar a duração de ritmos, a representação do tempo, por exemplo, situar-se nos dias da semana e horas ou até mesmo a orientação espacial, parece revelar um modo de ser particular: a criança hiperativa vive no imediatismo, na instantaneidade.

2. A autoridade do adulto e o acolhimento do sintoma - Normalmente, essas crianças não seguem instruções, perturbam a aula ou a família, não respeitam regras de jogos ou brincadeiras, etc. Em alguns momentos, este comportamento, embora também revele uma criança muito divertida e ativa, desperta nos adultos uma sensação de impotência, dada a dificuldade de impor limites, manter fronteiras e agir com autoridade. A excitação hiperativa gera uma conduta de repreensão ou punição. Saber encontrar o equilíbrio pedagógico e psicoterapêutico é, então, tarefa de um terapeuta experiente, reconhecido como autoridade e capaz de oferecer liberdade ao sujeito e respeitar sua singularidade perturbadora. É provável que a possibilidade da utilização de um medicamento, a Ritalina, tenha transformado os diversos aspectos que envolvem essa questão em uma dimensão ainda pouco explorada. O pensamento e a teoria, que podem desempenhar um papel ativo no cuidado, competem agora com um fármaco, cuja eficácia é objetiva, embora trate apenas o sintoma e pouco considere o processo de elaboração e desenvolvimento deste transtorno.

3. A construção da fronteira - Como um ambiente de cuidado pode ajudar uma criança a desenvolver outras modalidades, investir no pensamento e suportar a inação, transformar a excitação em prazer de jogar, brincar? A primeira tarefa é ter o limite espacial e temporal dentro de sua dupla função de lugar e de diferenciação: uma fronteira considerada como lugar de proteção e de trocas. A continuidade e regularidade dos encontros e a organização de sequências nas sessões são condições essenciais ao cuidado. A fronteira ao senso espacial do termo se constitui no trajeto para ir ao centro, nos contatos com os educadores, pais e vizinhos. Essa diferenciação entre interior e exterior envolve respeitar os espaços em um mesmo local, de acordo com a funcionalidade definida por adultos (sala de atividades, biblioteca, escritórios, hall de entrada, banheiros etc), e a interpretação das próprias crianças (o local onde se pode esconder, a porta que deverá permanecer fechada, etc.). Assim, sentir e se apropriar do espaço de cuidado vem em primeiro lugar para que a criança vivencie a experiência de encontrar um lugar no grupo.

4. A distância - No grupo de Léo (participante do relato de experiência do autor), foi introduzido, durante as sessões, um jogo utilizado pelas crianças em momentos de mudanças de atividades, mas, especialmente, quando se separavam e aguardavam pelos pais. Trata-se do "Touche", cuja regra é simples: quem é tocado deve, por sua vez, tocar outra criança, restabelecer a liberdade de fugir. $O$ jogo exclui adultos, que são ignorados. Esse jogo organiza uma representação de toda a necessidade de estar em contato com o outro, o desejo de capturar e o medo de ser devorado. Por meio da mediação de objetos (da casa, criados pelo grupo e produzidos pelas próprias crianças) e mediante o ir e vir entre o espaço do grupo e o espaço individual, são estabelecidas uma distância do outro e uma representação de ausência. A ansiedade da separação, a sexualidade, o medo dos adultos e a perda podem ser simbolizados e tolera-se a expressão das emoções de afetos.

"Ao ceder palavras, cedemos ideias... ao ceder modelos, cedemos práticas" (p.5). Com essas palavras, Golse (2003) incentiva uma reflexão que vai além de um mero problema de hiperatividade da criança e de um pedido da sociedade à pedopsiquiatria, pois suscita pensar também sobre o impacto de tais práticas e modelos nessa psicopatologia. Em geral, os proble- 
mas mentais, particularmente das crianças, não são do ponto de vista terminológico doenças como as outras, isto é, moléstias comparáveis a doenças somáticas. As doenças psiquiátricas não são, geralmente, identificáveis por algum marcador biológico específico e seu reconhecimento, assim como sua identificação com respeito à normalidade ou comparação com outras doenças, não pode se fundamentar em um único consenso. Esse tipo de consenso, que não é "medido", dá lugar a classificações nosográficas que dependem de um determinado contexto: científico, social e cultural.

Nesse aspecto, observa-se uma incipiência na apresentação de publicações acerca dessa temática no Brasil, o que parece sugerir que o tema ainda é pouco abordado e necessita de mais estudos e publicações. Consideram-se os resultados disponíveis preocupantes, pois, uma vez que se fala de humanização, integralidade, universalidade, especialmente no âmbito da saúde, não há como olhar o problema mental na infância somente sob o prisma de classificações advindas do modelo biomédico.

No Brasil, à semelhança do que se demonstrou em outros países, é insuficiente o conhecimento acerca do TDA/H, tanto na população em geral quanto em profissionais envolvidos no seu diagnóstico e tratamento. Embora os médicos e os psicólogos tenham demonstrado ser o grupo com maior nível de conhecimento, ainda há lacunas e contradições explicitadas no auto-relato desses profissionais acerca do tema. É urgente o estabelecimento de um programa de capacitação e educação continuada para profissionais que lidam com TDA/H, especialmente clínicos gerais e pediatras, educadores e psicólogos, assim como um efetivo programa de informação aos pais e escolas, de forma a garantir o diagnóstico correto e o tratamento bem-sucedido dos portadores de TDA/H (Gomes, 2007, p. 101).

A doença permanece em nosso mundo atual como uma identidade social negativa, porque o que se deseja é saúde (CANGUILHEM, 2002). Estar doente é ser indesejável, prejudicial ou socialmente desvalorizado. No nível físico e ainda mais no caso do TDA/H, a criança pode tornar-se estigmatizada em seus ambientes pelos quais deve sentir-se segura, como família e escola. A versão idealista da OMS é confusa, impossibilitando sua avaliação. É que saúde como saúde mental são conceitos esquivos, além de qualquer possibilidade de definição exaustiva. Essas mesmas noções são permeáveis uma à outra; a saúde influencia a saúde mental e vice-versa e envolve uma dinâmica social inegável, pois é difícil identificar quais processos socioculturais produzem ou minam o processo de saúde mental. Lazaratou e Golse (2018), depois de terem evocado os limites da nosografia no campo da patologia mental e os fundamentos epistemológicos dos diferentes modelos etiológicos de hiperatividade, os autores discutem a história do próprio conceito do TDA/H em relação às últimas edições do DSM: (III, IV e V), enfatizando as ambiguidades dos critérios de diagnóstico. Além disso, eles realizaram uma revisão da literatura, mostrando as diferenças existentes de acordo com os locais e os contextos das prevalências dessa patologia específica, antes de listar um certo número de trabalhos centrados no diagnóstico ou no tratamento, e que mostram grandes diferenças dependendo do contexto cultural.

\section{Considerações finais}

O presente artigo apresentou reflexões acerca do TDA/H privilegiando os aspectos socioculturais, as quais contemplaram os objetivos do estudo. Destaca-se a ideia de que a criança não busca ajuda sozinha. Comumente, ela é trazida aos especialistas da saúde pelos pais, às vezes orientados pelos professores, que percebem naquela criança algo diferente ou estranho. Se esse diferente é algo que está na concepção dos pais e eles estão tendo dificuldade em lidar com o filho da forma que ele é, se é apenas o jeito da criança e isso não é um problema para ela, ou se isso é, de fato, uma patologia com necessidade de intervenção, são lados a serem pensados e 
considerados. Dessa forma, é importante sempre analisar o lado adulto impondo regras e limites, e o lado da criança procurando viver sua essência infante.

Assim, os profissionais da saúde e da educação devem estar familiarizados diante dos padrões de comportamentos normais e desviantes e considerar, em seus conceitos, avaliações e ações, a cultura, as crenças, o entorno e as especificidades de cada criança. Mais pesquisas transculturais e empíricas são necessárias para compreender como os contextos específicos do TDA/H estão incorporados e moldados por uma universalidade de protocolos de diagnósticos e modelos biomédicos.

\section{Referências bibliográficas}

ADHD INSTITUTE Epidemiology. Suiça,2018. Retirado de: https://adhd-institute.com/.

Bader, M., \& Mazet, P. (2015). Le concept du TDA/H et la France de 1890 à 1980: l'instabilité ou le village gaulois d'Asterix?. La psychiatrie de l'enfant, 58(2), 609-663.

Beltrame, R. L., Souza, S. V. D., Nascimento, D. M. D., \& Sandrini, P. R. (2015). Ouvindo crianças sobre sentidos e significados atribuídos ao TODA/H. Psicologia Escolar e Educacional, 19(3), 557-565.

Calixto, F. G. C., Soares, S. L., \& Paixão, F. U. (2021). A APRENDIZAGEM E O TRANSTORNO DO DÉFICIT DE ATENÇÃO E HIPERATIVIDADE: UMA ANÁLISE DA PRODUÇÃO BRASILEIRA. Revista Contexto \& Educação, 36(113), 74-84.

Canguilhem, G.(2002). O normal e o patológico. Rio de Janeiro: Forense Universitária.

Chagnon, J. Y. (2005). Hyper-actifs ou hypo-passifs? La psychiatrie de l'enfant, 48(1), 31-88.

De Oliveira, H. M. A. C. (2020). Experiências de vida de mães com filhos com PHDA (Doctoral dissertation).

De Sousa, R. J. G., Vieira, R., Almeida, S. R. A., \& Feijó, M. R. (2021, January). A importância do trabalho interdisciplinar em saúde mental no tratamento de sintomas de ansiedade, depressão e TDA/H em criança. In Anais do III Congresso de Saúde Mental da UFSCar.

Duarte, S. D. (2013, abril). Atenção à saúde mental de crianças precisa ser melhorada. Entrevistador Agência Fapesp: Elton Alisson. Retirado de: http://agencia.fapesp.br/atencao_a_saude_ mental_de_criancas_precisa_ser_melhorada_/17079/

Fourneret, P. (2003). À propos de l'enfant instable: aperçu historique et point de vue épistémologique. Le Carnet Psy, (1), 13-14.

Gilloots, M. (2002). Un enfant superactif. La lettre de l'enfance et de l'adolescence, (2), 63-70.

Gilloots, M. (2013). Hyperactivité et sexualité infantiles. Enfances Psy, (4), 141-149.

Gingerich, K. J., Turnock, P., Litfin, J. K., \& Rosén, L. A. (1998). Diversity and attention deficit hyperactivity disorder. Journal of clinical psychology, 54(4), 415-426. 
Golse, B. (2003). L'hyperactivité de l'enfant: un choix de société. Le Carnet PSY, (1), 26-28.

Gomes, M., Palmini, A., Barbirato, F., Rohde, L. A., \& Mattos, P. (2007). Conhecimento sobre o transtorno do déficit de atenção/hiperatividade no Brasil. Jornal Brasileiro de Psiquiatria, 56(2), 94-101.

Gonçalves, A. M. (2004). A doença mental e a cura: um olhar antropológico. Millenium, 159-171.

Günter, M. (2015). Trouble du déficit de l'attention avec hyperactivité (TDA/H): un trouble de la transformation des affects et de la pensée? LAnnee psychanalytique internationale, 2015(1), 121-154.

Joly, F. (2003). La peste ou le choléra. Le Carnet PSY, (1), 1-1.

Kleinman, A. (2008). Rethinking psychiatry. Simon and Schuster.

Lawrence, K., Estrada, R. D., \& McCormick, J. (2017). Teachers' experiences with and perceptions of students with attention deficit/hyperactivity disorder. Journal of pediatric nursing, $36,141-148$.

Lazaratou, H., \& Golse, B. (2018). L'hyperactivité, entre Biologie et culture. La psychiatrie de l'enfant, 61(1), 179-198.

Le Heuzey, M. F. (2017). Hyperactivité: attention, souffrance!. Sciences Humaines, (4), 6-6.

Mohr-Jensen, C., \& Steinhausen, H. C. (2016). A meta-analysis and systematic review of the risks associated with childhood attention-deficit hyperactivity disorder on long-term outcome of arrests, convictions, and incarcerations. Clinical psychology review, 48, 32-42.

Mulholland, S. M., Cumming, T. M., \& Jung, J. Y. (2015). Teacher attitudes towards students who exhibit ADHD-type behaviours. Australasian Journal of Special Education, 39(1), 15-36.

Muniz, R. O. B. (2019). Família e escola a ausência da família na vida escolar das crianças do 5 ㅇ ano em uma escola do município de Parintins.

Nogueira, C. P., Barbosa, M. R., \& Barbosa, L. A. R. R. (2016). Transtorno Do Déficit De Atenção com Hiperatividade e o Olhar dos Professores: Uma Revisão Integrativa. Revista Brasileira de Pesquisa em Ciências da Saúde, 2(2), 60-68.

Petitot, F. (2005). D'un trouble à l'autre. La lettre de l'enfance et de l'adolescence, (4), 5-8.

Petitot, F. (2007). Enfant turbulent ou enfant troublé? La lettre de l'enfance et de l'adolescence, (1), 65-70.

Prado-Martin, M. R. (2015). La médicalisation des difficultés d'apprentissage au Brésil: la montée du diagnostic de TDA/H. Revue de l'enfance et de l'adolescence, (2), 107-120.

Roman, P. (2003). L'hyperactivité infantile et les épreuves projectives: une proposition méthodologique. Le Carnet PSY, (1), 30-31.

Rohde, L. A., Barbosa, G., Tramontina, S., \& Polanczyk, G. (2000). Transtorno de déficit de atenção/hiperatividade. Brazilian Journal of Psychiatry, 22, 07-11. 
Rosa, S. A. D. (2011). Dificultades de atención e hiperactividad en la perspectiva histórico-cultural. Psicologia escolar e educacional, 15(1), 143-150.

Rousseau, C., Measham, T., \& Bathiche-Suidan, M. (2008). DSM IV, culture and child psychiatry. Journal of the Canadian Academy of Child and Adolescent Psychiatry = Journal de I'Academie canadienne de psychiatrie de l'enfant et de l'adolescent, 17(2), 69-75.

Zayats, T., \& Neale, B. M. (2019). Recent advances in understanding of attention deficit hyperactivity disorder (ADHD): how genetics are shaping our conceptualization of this disorder. F1000Research, 8, F1000 Faculty Rev-2060. https://doi.org/10.12688/f1000research.18959.2 